\title{
A Neurotropic Potential for Brain Damage in COVID-19
}

\author{
Stefan Bittmann*, Elisabeth Luchter, Elena Moschüring Alieva, Anne Weissenstein and Gloria \\ Villalon
}

Head, Department of Pediatrics, Ped Mind Institute (PMI), Gronau, Germany

*Corresponding author: Stefan Bittmann, Head, Department of Pediatrics, Ped Mind Institute (PMI), Gronau, Germany

\begin{tabular}{|c|c|}
\hline ARTICLE INFO & ABSTRACT \\
\hline Received: 慧 April 06, 2020 & Citation: Stefan Bittmann, Elisabeth Luchter, Elena Moschüring Alieva, Anne \\
\hline Published: 慧 April 14, 2020 & $\begin{array}{l}\text { Weissenstein, Gloria Villalon. A Neurotropic Potential for Brain Damage in COVID-19. } \\
\text { Biomed J Sci \& Tech Res 27(1)-2020. BJSTR. MS.ID.004437. }\end{array}$ \\
\hline
\end{tabular}

\section{Editorial}

SARS-CoV-2 binds to the angiotensin II receptor on various tissues in the human body, especially in the oral cavity and tongue. SARS-CoV-2 requires the serine protease TMPRSS2 for this binding. SARS-CoV-2 uses the ACE2 receptor as an entry portal into the lung [1]. The SARS-CoV-2 virus binds with the spike protein to the ACE2 receptor [1]. The spike protein has a functional multiphase furin cleavage site at S1/S2 by insertion of 12 nucleotides and shows mutations at the receptor binding domain (RPD) with binding to 6 RBD amino acids. Due to the binding domain at the angiotensin II receptor, angiotensin receptor blockers are possible alternatives for the treatment of children with severe COVID-19 infection. To date, there is no clinical experience with COVID-19-positive children and no study on this topic. In adults, a randomized controlled trial (Losartan/Plecebo) for 200 patients with severe COVID-19 infection requiring hospitalization was initiated at the University of Minnesota on March 16, 2020 [2].

The expression and distribution of ACE2 in the human body may indicate the possible routes of infection of 2019-nCoV. Using the developed single cell RNA sequencing technique (scRNA-Seq) and single cell transcriptomes based on the public database, the researchers developed an ACE2 RNA expression profile with single cell resolution. High expression of ACE2 was identified in type II alveolar cells (AT2) of the lung, in upper and stratified epithelial cells of the esophagus, in absorptive enterocytes from ileum and colon, in cholangiocytes, in myocardial cells, in proximal tubule cells of the kidney and in urothelial cells of the bladder. These results showed that those organs with strongly ACE2-expressing cells should be considered potentially at high risk for $\mathrm{nCoV}$ infection in 2019 [1]. The study by Xu et al. showed a superiority of COVID-19 virus over ACE2 receptors in the oral cavity and tongue, suggesting that COVID-19 reaches a part of the body in this way [1]. ACE2 and his receptors are also found in the brain, especially in CNS neurons of glial cells. The brain expresses ACE 2 receptors in a wide number [3]. They have been detected over glial cells and neurons, suggesting that COVID-19 is a potential target for the brain of human beings [3]. Previous studies have demonstrated the ability of SARS-CoV to cause neuronal death in mice by entering the brain through the nose near the olfactory epithelium [4].

The contribution of the neurotropic potential of SARS-CoV-2 in patients reported in the recent outbreak of COVID-19 remains to be determined. For SARS-CoV infections reported in the past, patient autopsy findings using electron microscopy, immunohistochemistry and reverse real-time transcriptional PCR have shown strong evidence of the presence of SARS-CoV [4]. Patients with acute SARS$\mathrm{CoV}$ disease have also demonstrated the presence of the virus in CSF. The role of the blood-brain barrier in containing the virus and preventing its access to nervous tissues needs further investigation in patients diagnosed with COVID-19. Also, a finding published in a patient who lost involuntary respiratory control during the recent outbreak, along with several other patients with acute respiratory failure [5], calls on professionals and clinicians to separate COVID-19 patients into those with neurological manifestations and those without neurological deficits. A study published in medRxiv, 214 COVID-19 patients were ruled out and $36.4 \%$ had neurological symptoms, which indicates a neurotropic potential of COVID-19 [6].

Recent case reports in adults shed light on brain damage of COVID-19 with deterioration, loss of speech, loss of taste and presence of COVID-19 triggered necrotic encephalitis [7,8]. Typical 
CT and MRI features were found in a female airline worker with a 3-days history of cough, fever, and bad mental condition and COVID-19 positive viral swab [9]. Non contrast head CT showed symmetric hypoattenuation in the region of bilateral medial thalami [10]. Images from brain MRI showed hemorrhagic rim enhancing lesions within the thalami on both sides, medial temporal lobe region and subinsular region [11]. The female patient was treated with intravenous immunoglobulin. Acute necrotizing encephalopathy (ANE) is a rare complication and most often triggered by viral agent. COVID-19 seems to trigger an intracranial cytokine storm, which leads to blood-brain barrier breakdown with induction of direct viral invasion and parainfectious demyelination [12]. COVID-19 seems to have a neurotropic potential, which have to be ruled out by further research and retrospective case studies.

\section{References}

1. Xu H, Zhong L, Deng J, Peng J, Dan H, et al. (2020) High expression of ACE2 receptor of 2019-nCoV on the epithelial cells of oral mucosa. International Journal of Oral Science 12: 8.

2. Clinical Trial Randomized controlled trial of Losartan for patients with COVID 19 requiring hospitalization. Clinical Trials gov, Identifier: NCT 04312009, University of Minnesota.

3. Bang AM, Khaleeq A, Ali U, Siede H (2020) Evidence of the COVID-19 VIRUS targeting the CNS: Tissue distribution, Host-Virus Interaction, and Proposed Neutrotropic Mechanism. ACS Chemical Neuroscience 11: 995-998.

ISSN: $2574-1241$

DOI: 10.26717/BJSTR.2020.27.004437

Stefan Bittmann. Biomed J Sci \& Tech Res

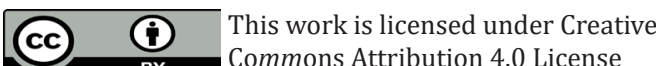

Submission Link: https://biomedres.us/submit-manuscript.php
4. Netland J, Meyerholz DK, Moore S, Cassell M, Perlman S (2008) Severe acute respiratory syndrome coronavirus infection causes neuronal death in the absence of encephalitis in mice transgenic for human ACE2. J Viro 82(15): 7264-7275.

5. Flaten HK, Monte AA (2017) The pharmacogenomic and metabolomic predictors of ACE Inhibitor and Angiotensin II Receptor Blocker Effectiveness and Safety. Cardiovasc Drugs There 31 (4): 471-482.

6. Rossi A (2008) Imaging of acute disseminated encephalomyelitis. Neuroimaging Clinics 18(1): 149-161.

7. Jiao F, Bittmann S (2020) A new classification of clinical findings and treatment options of SARS-CoV-2 infection in children from China. Advances in Pediatric.

8. Nwaiwu O, Olayemi SO, Amao O (2015) Use of angiotensin II receptor blockers in children-A review of evidence. Niger J Paed 42 (3): 180-187.

9. Flaten HK, Monte AA (2017) The pharmacogenomic and metabolomic predictors of ACE Inhibitor and Angiotens in II Receptor Blocker Effectiveness and Safety. Cardiovasc Drugs There. 31(4): 471-482.

10. Poyiadji N, Schien G, Noujaim D, Stone M, Patel S, et al. (2020) Covid-19 associated Acute Hemorrhagic Necrotizing Encephalopathy: CT and MRI Features. Images in Radiology 31(1): 5-30.

11. Mao L, Wang M, Chen S, He Q, Chang J, Hong C, et al. (2020) Neurological manifestations of Hospitalized Patients with COVID-19 in Wuhan, China: A retrospective case series study. med Rxiv.

12. Li YC, Bai WZ, Hashikawa T (2020) The neuro invasive potential of SARSCoV-2 may be atleast partially responsible for the respiratory failure of COVID-19 patients. J Med Virol.

$\begin{array}{ll}\text { BIOMEDICAL } & \text { Assets of Publishing with us } \\ \text { RESEARCHES } & \text { - Global archiving of articles } \\ & \text { - Immediate, unrestricted online access } \\ & \text { - Rigorous Peer Review Process } \\ & \end{array}$

